\title{
Northern Ireland's longstanding record wind gust is almost certainly incorrect
}

\section{Article}

Accepted Version

Aylott, L., Burt, S. and Saunders, M. (2020) Northern Ireland's longstanding record wind gust is almost certainly incorrect. Weather, 75 (1). pp. 8-13. ISSN 0043-1656 doi: https://doi.org/10.1002/wea.3613 Available at https://centaur.reading.ac.uk/86756/

It is advisable to refer to the publisher's version if you intend to cite from the work. See Guidance on citing.

To link to this article DOI: http://dx.doi.org/10.1002/wea.3613

Publisher: Wiley

All outputs in CentAUR are protected by Intellectual Property Rights law, including copyright law. Copyright and IPR is retained by the creators or other copyright holders. Terms and conditions for use of this material are defined in the End User Agreement.

\section{www.reading.ac.uk/centaur}

\section{CentAUR}

Central Archive at the University of Reading

Reading's research outputs online 


\title{
Northern Ireland's longstanding record wind gust is almost \\ 2 certainly incorrect
}

\author{
Lucy Aylott ${ }^{1}$, Stephen Burt ${ }^{1}$ and Mark Saunders ${ }^{2}$ \\ ${ }^{1}$ Department of Meteorology, University of Reading. \\ 2 Department of Space and Climate Physics, University College London.
}

4

6 Author for correspondence:

Professor Mark Saunders, Department of Space and Climate Physics, University College London,

(m.saunders@ucl.ac.uk)

Keywords: Wind gust, extreme, record, Northern Ireland, verification, anemograph, return period.

$9^{\text {th }}$ August 2019

\footnotetext{
Abstract

Accurate assessment of record extreme wind gusts is important for building design standards and for industries such as insurance and forestry. Here we show that the current record wind gust for Northern Ireland - $108 \mathrm{kn}\left(56 \mathrm{~m} \mathrm{~s}^{-1}\right)$ recorded at Kilkeel on 12 January 1974 - is almost certainly incorrect, and may have arisen from an instrumental error or a power surge. We deduce this from direct anemograph inspection and from a variety of indirect supporting evidence. We recommend that other longstanding United Kingdom record wind gusts should also be independently re-examined to assess their veracity.
} 


\section{Introduction}

High winds accompanying severe extra-tropical cyclones (windstorms) are a significant natural hazard for the United Kingdom (UK) (Shellard, 1976; Palutikof et al., 1997). These winds cause damage to buildings and forestry, disruption to transport and power supplies, and loss of life (Blackmore and Tsokri, 2004; Hewston and Dorling, 2011; Department for Transport, 2014). The impacts from windstorms are characterized usually in terms of their peak gusts rather than maximum mean wind speeds (Prahl et al., 2015). In the context of modern digital anemometer sensors, a 'gust' is defined as the temporary maximum of the 3 second moving average wind speed; a definition formalised and maintained by the World Meteorological Organization (WMO) (WMO, 1987; 2014), following the work of Beljaars (1987). However, the duration of gusts recorded on older analogue equipment that use a paper chart is less easily determined (see Box: Historical wind records - a brief review).

The underpinning role held by wind gusts in relating windstorm intensity to windstorm impacts means that it is crucial - both scientifically and for users - that extreme wind gusts are documented accurately. Record wind gusts can influence building design standards, insurance pricing and the identification of locations where transport networks and forestry are most vulnerable to high winds. For example, users of wind data often require knowledge of the 50-year gust return period (Palutikof et al., 1999). As there may be less than 50 years of observations with which to make such calculations, the impact on users of an erroneous extreme gust can be considerable (Cook, 2014), especially if it represents the highest gust on the available record. Of course, there are other sources of uncertainty with regard to wind record homogeneity, including those arising from changes of instrument and thus recording characteristics (including response time) during the period of record, changes in site and exposure which may or may not be fully documented, variations in manual record analyses, and the quality of analogue-to-digital data conversions. However, these other factors are less relevant to the focus of this article.

\section{BOXED TEXT}

\section{Historical wind records - a brief review}

From its introduction in 1892 until about 1955 nearly all autographic records of wind speed, including gusts, in the UK and the Republic of Ireland originated from Dines pressure-tube anemographs (Dines PTAs) (Met Office, 1981; Pike, 1989). Between about 1955 and 1975 in the UK, the older Dines PTAs were gradually superseded by the modern day electrical rotating cup anemometer. These cup anemometers were included in early digital wind measurement systems commencing in the 1970s and then in integrated automatic weather stations from the late 1980s onwards.

The homogeneity of wind records, particularly gust speeds, between the Dines PTA and electrical rotating cup anemometer has been brought into question. Smith (1981) examined the differences in 10 minute and hourly 
mean wind speeds recorded by both instruments, finding that the rotating cup anemometer produced mean wind speeds 5\% higher than the PTA during high winds, although the analysis did not extend to gust speeds. Miller et al. (2013) found that gusts recorded by the Dines PTA were 5-10\% higher than those recorded by a cup anemometer under the same conditions, and that these differences increased with adoption of the WMOrecommended $3 \mathrm{~s}$ gust definition. The typical gust averaging period obtained from an anemograph trace is stated as $1.5 \mathrm{~s}$ in the Met Office Surface Data Users Guide (Met Office, 2019b, Section 5.5; Hewston and Dorling, 2011), although no source for this statement is specified and $1.5 \mathrm{~s}$ seems unrealistically low. While calibration errors of around 5\% that are also applied to the gust speeds from anemographs may act to offset differences between $1.5 \mathrm{~s}$ and $3 \mathrm{~s}$ gust measurement periods (Burt, 2012, Chapter 9, Figure 9.5; Met Office, $2019 b$ ), the periods when these calibration errors occurred do not appear to be properly documented (Hewston and Dorling, 2011). Cook (2014) found that following full automation in 1995 of the process to generate and archive wind data in the Met Office that virtually all incorrect data artefacts have been removed. However, preautomation wind and gust data still comprise a substantial part of the historical archive.

(1)

In the UK, lists of weather and climate extremes are documented and published online by the Met Office (Met Office 2019a). With specific regard to extreme wind gust records, Met Office online notes clarify that published values for 'record' gust speeds are based exclusively on more recent observations (1969 onwards), exclude stations above $500 \mathrm{~m}$ altitude, and that attempts have been made to verify these records by comparison with nearby stations. However, to our knowledge, these record gust values have not undergone independent scrutiny and verification, and may well have remained unchecked since the time of their initial recording. This matter is considered in more detail subsequently.

On 12 January 1974, a gust of 108 kn was reported from Kilkeel in Northern Ireland during an intense extratropical cyclone. This established a new Met Office record for the highest gust speed at a low-level station in Northern Ireland; a record that remains in place to date (Met Office, 2019a). At the time of the gust, the Kilkeel weather station was equipped with an electrical-recording cup anemometer system, which produced a paper chart record (an anemogram).

The article is structured as follows. An overview of the synoptic situation leading to the extreme gust measurement at Kilkeel is given, followed by a review of the wind data recorded during the storm at other sites in the UK and in the Republic of Ireland. The Kilkeel anemogram for the 'record' gust is then presented and carefully examined, after which we assess the evidence for and against the veracity of the gust. The article concludes by discussing the implications of our findings, and by recommending the creation of an independent review committee to improve the compilation, adjudication and publication of record UK wind gusts and, by implication and extension, for other UK weather extremes.

\section{Synoptic overview and storm damage}

The extreme gust at Kilkeel was recorded at 0536 GMT on 12 January 1974 during the close passage of an intense extratropical cyclone. This storm and its impacts are noted briefly in Lamb (1991) and 
in Eden (2008). Figure 1 shows the nature, track and strength of the extratropical cyclone during the

24 hours spanning the Kilkeel gust event, as documented in the Daily Weather Report (Met Office, 1974a). The storm deepened explosively (defined as a central pressure fall of at least $24 \mathrm{hPa}$ in $24 \mathrm{~h}$; Sanders and Gyakum, 1980) to the south-west of Ireland on 11 January (not shown) with its central pressure falling to $960 \mathrm{hPa}$ by $1800 \mathrm{GMT}$ (Figure 1a). The occluding depression then moved northeastward somewhat to the west of Ireland and Scotland between 0000 and 1200 GMT 12 January, attaining a minimum central pressure of $956 \mathrm{hPa}$ at $0600 \mathrm{GMT}$, at which time the depression was centred to the north-west of Ireland (Figure 1c). A very strong pressure gradient developed across the British Isles between 0000 and 1200 GMT on 12 January: a Met Éireann report (Keane and Sheahan, 1974) states that the geostrophic gradient wind speed reached $145 \mathrm{kn}$ to the south and south-east of the depression centre at about $0600 \mathrm{GMT}$, although evidence for this statement was not quantified. An unstable returning polar maritime airmass was introduced behind the system's cold front (Figure 1c), and by 1200 GMT (Figure 1d) gradient winds began to moderate over Ireland as the depression moved away to the north-west of Scotland.

The windstorm of 11-12 January 1974 caused extensive damage in the Republic of Ireland (Keane and Sheahan, 1974). The sustained high winds and extreme gusts uprooted thousands of trees causing severe disruption to transport as a result of blocked roads and railway lines. There was widespread damage to buildings, especially to roofs, chimneys, windows and exposed walls, and three lives were lost. The windstorm caused considerable power and telephone outages with some electricity supplies taking a week to be restored. At the time, the Irish Electricity Supply Board, established in 1927, described the storm as the "worst disaster in the history of the Board". Sixty percent of the Electricity Supply Board's damage bill occurred in the south-western and southern counties of Kerry, Cork, Limerick, and Waterford, where the greatest mean wind speeds were recorded. The storm damage was exacerbated by storm surge in some coastal areas.

In contrast to the widespread damage that occurred in the Republic of Ireland during this windstorm, there are few reports of significant damage in Northern Ireland or in other areas of the UK other than the less severe damage levels expected from a storm whose peak gusts reached 60-70 kn. However, a gust of $114 \mathrm{kn}$ was measured during the event at Great Dun Fell, an exposed highlevel site (847 m elevation) in the Pennines (Met Office, 1974b).

\section{Surface wind observations}

Wind gusts during the 11-12 January 1974 windstorm are examined here for the 24 anemometer sites shown in Figure 2. These stations comprise the 15 Met Éireann stations whose storm maximum gusts are reported by Keane and Sheahan (1974), five of which experienced new gust speed records to that 
date, and nine Met Office/UK stations, namely Kilkeel and the eight stations located closest to

Kilkeel in Northern Ireland and bordering the Irish Sea. The UK station data come from the Met Office Integrated Data Archive System (MIDAS) (Met Office, 2012) and consist of hourly mean winds and hourly peak gusts.

Table 1 sets out the maximum recorded gusts at the Met Éireann stations. The two highest gusts during the storm were $94 \mathrm{kn}$ at Cork Airport and $86 \mathrm{kn}$ at Valentia. Both sites are located in southwest Ireland (Figure 2). The stations located in eastern Ireland (Casement Airport, Dublin Airport and Rosslare) that have an exposure and wind fetch similar to that of Kilkeel all recorded maximum gusts between 75 and $77 \mathrm{kn}$, some $30 \mathrm{kn}$ lower than the reported $108 \mathrm{kn}$ gust at Kilkeel.

Figure 3 compares the hourly mean wind speeds and hourly maximum gusts recorded at Kilkeel with the same wind parameters recorded at the nearest eight Met Office stations for the 24 hour period centred on the Kilkeel gust event. All nine sites show similar profiles in hourly mean wind (Figure 3a) and hourly maximum gust (Figure 3b). For the hour ending 0600 GMT, the hourly mean wind speed at Kilkeel $(53 \mathrm{kn})$ was slightly higher than at any other station, although at Valley on Anglesey (Figure 2) the hourly mean was very similar (51 kn). With the exception of the $108 \mathrm{kn}$ gust in question, Figure $3 b$ shows that the hourly maximum gust speeds at Kilkeel were in line with those at the other stations.

\section{Kilkeel anemogram}

The original anemogram for the Kilkeel record wind gust is shown in Figure 4. The extreme gust spike identified as the $108 \mathrm{kn}$ record wind gust is marked as 'Record S1' and is clearest in the magnified anemogram portion in Figure $4 b^{1}$. It is believed that this anemometer was equipped with an automatic range-change device designed to trigger the chart recorder pen to record at half scale once the wind speed exceeded $70 \mathrm{kn}$. The half-scale device required manual resetting in order to return to the default scale (Met Office, 1981). It should be noted when interpreting the anemogram that this half-scale device was in operation between approximately 0440 and 0840 GMT, evident from the apparent halving in wind speed at $\sim 0440$ GMT and from the abrupt doubling in wind speed at $\sim 0840$ GMT: the switch to half-scale recording appears to have been triggered automatically by a gust of $69 \mathrm{kn}$, while the return to full-scale recording appears to have resulted from a manual reset by the observer on duty.

\footnotetext{
${ }^{1}$ As the response time of the instrument in use at the time is unknown, it is impossible to state whether the gusts recorded on the Kilkeel anemograph correspond directly to the current WMO gust definition of the 3 second moving average wind speed (WMO, 2014), or to a longer period average. If the latter was the case, then the equivalent 3 second gusts would be higher than the spikes evident on the Kilkeel anemograph.
} 
Inspection of Figure 4 shows that during the period when the instrument was in 'half-scale' mode, five extreme spikes occur on the wind speed record. We mark these spikes as S1 to S5 on the enlarged portion of the anemograph trace in Figure $4 \mathrm{~b}$ and provide the times and gust speeds for these spikes in Table 2. The $108 \mathrm{kn}$ and $84 \mathrm{kn}$ lines (spikes S1 and S4) were accepted as legitimate gusts in the MIDAS dataset (Met Office, 2012), and remain so, but the other spikes were not. If these five anomalous spikes are discounted, the next highest recorded gust is $78 \mathrm{kn}$ at 0619 GMT.

The five anomalous gust spikes in Figure 4 and Table 2 appear very similar in nature. All occur suddenly and in isolation to any similar strength gust. This behaviour seems unnatural and out of character with the other Kilkeel gust data in Figure 4. Furthermore, none of the spikes is associated with any change in wind direction as might be expected to occur at a sharp gust front. As the three most extreme spikes on the anemogram (S2, S3 and S5, corresponding respectively to gusts of 190, 162 and $190 \mathrm{kn}$ ) cannot be genuine gusts, it is reasonable to infer that the two smaller but similar spikes are also spurious.

\section{Compilation and assessment of evidence}

A further cogent reason for questioning the accuracy of the $108 \mathrm{kn}$ gust at Kilkeel is its vast return period, assessed as being in excess of 1 million years. This return period was deduced by applying the method of independent storms with a robust peak-over-threshold extreme value analysis to all the Kilkeel hourly gust data from 1969 (Saunders and Lea, 2017). Also telling is that the second-highest gust recorded at Kilkeel in all other extra-tropical cyclones between 1969 and 2013 was 'only' 75 kn, 30 per cent lower than the extreme gust in question. Related to this, it is worthwhile to note that, after discounting the seemingly anomalous spikes on the anemogram in Figure 4, the highest remaining gust of $78 \mathrm{kn}$ on 12 January 1974 would still rank as the highest recorded gust at Kilkeel between 1969 and 2013.

Table 3 lists the evidence for and against the veracity of the $108 \mathrm{kn}$ gust at Kilkeel. The three points in support of the 'gust' being genuine are the best reasons that we can offer, but in our opinion all three reasons are weak. The occurrence of high hourly mean winds at Kilkeel is beyond dispute, although these mean winds were broadly comparable to those experienced elsewhere during the storm in question. In contrast, the maximum gusts recorded at these same sites were considerably lower than the $108 \mathrm{kn}$ reported from Kilkeel. Similarly, the occurrence of significant storm damage in the Republic of Ireland is simply consistent with the highest storm gusts occurring in the south-west and south of the country, and is not supportive evidence for a $108 \mathrm{kn}$ gust at Kilkeel.

On the other hand, the evidence against the 'Kilkeel gust' being genuine is strong and compelling. The alleged gust is one of five sudden, unnatural and (we submit) spurious gust spikes 
recorded when the Kilkeel anemograph was operating in 'half-scale' mode on 12 January 1974. The three spikes that correspond to gusts of $190 \mathrm{kn}$ (twice) and $162 \mathrm{kn}$ cannot be real, as they far exceed both the current UK record low-level gust speed (123 kn, at Fraserburgh, Scotland, on 13 February 1989 ) and the UK record high-level gust speed (150 kn, on Cairngorm Summit, 1245 m elevation, on 20 March 1986) (Met Office, 2019a). Since the alleged $108 \mathrm{kn}$ gust is very similar in nature to other clearly spurious 'gust' events on the Kilkeel anemograph record it too is unlikely to be genuine. This direct anemograph evidence combined with strong indirect supporting evidence - namely the absence of reports of storm damage near Kilkeel compatible with gusts in excess of $100 \mathrm{kn}$, and the vast return period for the alleged record gust — leave little doubt that Northern Ireland's longstanding record wind gust is incorrect.

\section{Discussion}

What may have caused the sudden spurious gust spikes on the Kilkeel anemograph? Two possible explanations are that they arose either from an instrumental error or from brief surges in electrical power. The latter is realistic because the severe windstorm caused much disruption to power supplies across the Republic of Ireland (Keane and Sheahan, 1974). Since the Kilkeel anemograph record was electrical (rotation of the anemometer cups generating a voltage proportional to wind speed), the travel of the pen on the paper chart may have been susceptible to fluctuations in the mains electricity supply. External voltage surges can arise when power lines are brought down or, more commonly, when lightning strikes nearby electrical circuits leading to overhead power cables receiving a brief electrical spike. Although thunderstorms and lightning are rare in Northern Ireland in winter, Keane and Sheahan (1974) report that some cattle were killed by lightning during the 11-12 January 1974 windstorm, so there is evidence that thundery activity did occur during the event in question. Furthermore, Geurts (1975) reports the presence of considerable thundery activity on the cold front of the preceding depression which affected the British Isles on 11 January 1974, a day earlier.

Finally we note that, at the time of writing, all the current UK national (Scotland, Northern Ireland, Wales and England) records for low-level gust speed were set between 1969 and 1989 during the initial 21 years of digitized UK windspeed data (Met Office, 2019a). In contrast, no national record has occurred during the subsequent 29 year period between 1990 and 2018, despite the greater coverage by operational recording anemometers following automation of the Met Office station network (Green, 2010) and the occurrence of frequent winter windstorms including, recently, the stormy winter of 2013/14 (Kendon and McCarthy, 2015). Unless the intensity of windstorms resulting from intense extratropical cyclones affecting the British Isles has decreased since the 1970s and 1980s, the lack of entries appears odd to say the least, and raises questions about the veracity of 
other longstanding UK national record gust speeds. Indeed while performing our analysis of the

Kilkeel 'record' gust we re-examined two further UK national current record gust events, and found that the veracity of both is open to question. One event is a gust spike that resembles the Kilkeel anomalous gust spikes in appearance. The second event is ambiguous due to uncertainty about the change in windspeed scale. Both events have vast return periods assessed as being at least 100,000 years, and neither event appears associated with damage that is compatible with the reported gust levels.

\section{Conclusion and recommendation}

The evidence presented herein clearly shows that the longstanding 'record' $108 \mathrm{kn}$ gust at Kilkeel on 12 January 1974 was almost certainly not a genuine gust, that the anemograph record was probably affected by spikes in the electricity supply during the windstorm, and that the 'true' highest gust was $78 \mathrm{kn}$. Five potential power surges can be seen on the anemogram with two of these corresponding to gusts of $190 \mathrm{kn}$. The anemogram spike corresponding to the $108 \mathrm{kn}$ gust is very similar in nature to the four other anomalous spikes and is thus deemed untrustworthy. Furthermore there are no reports of storm damage in Kilkeel compatible with a gust as high as $108 \mathrm{kn}$, while the return period for such a gust has been assessed at over 1 million years.

Our research findings imply that other longstanding UK record wind gusts should also be independently re-examined to assess their veracity. To enable this, we recommend that an independent expert committee be appointed to examine, adjudicate upon and publish the official record values for all UK national and regional weather and climate extremes, including but not restricted to wind speed. This committee would have terms of operation similar to that of the WMO Global Archive of Weather and Climate Extremes (Purevjav et al., 2015) and of the National Climate Extremes Committee in the United States (Cerveny et al., 2007). Independent assessment of UK extreme weather records is particularly relevant for record gusts because these records are longstanding and there remain unresolved questions concerning the homogeneity of wind speed records made by older anemometer instruments (Smith, 1981; Miller et al., 2013; Cook, 2014). The creation of an independent weather and climate extremes committee in the UK would ensure the validity and reliability of extremes by collecting and assessing all the available evidence before such extremes are published in 'official' listings, and act to ensure permanent and secure archiving of all documentation related to the event.

\section{Acknowledgements and authors' contributions}


The authors are most grateful to Mark Beswick and Catherine Ross at the National Meteorological Library and Archive, and to the Public Record Office of Northern Ireland, for sourcing and providing the Kilkeel anemogram in Figure 4. We also thank Mark Beswick for his assistance in providing high quality charts for Figure 1. We thank Adam Lea at UCL for his help in preparing publication quality figures.

This article arises from work conducted by Lucy Aylott during an MSc dissertation at the University of Reading, supervised by Stephen Burt and Mark Saunders, that examined the nature and veracity of several UK record extreme gusts including the Kilkeel event. This project was conceived by Mark Saunders. All authors have contributed equally to the content of this article.

\section{References}

Beljaars, ACM, 1987. The influence on sampling and filtering on measured wind gusts. Journal of Oceanic and Atmospheric Technology, 4: 613-626. https://doi.org/10.1175/15200426(1987)004<0613:TIOSAF>2.0.CO;2

Blackmore P, Tsokri E. 2004. Windstorm damage to buildings and structures in the UK during 2002. Weather, 59: 336-339. https://doi.org/10.1256/wea.230.03

Burt S. 2012. The Weather Observer's Handbook. Cambridge University Press. 456 pp.

Cerveny RS, Lawrimore J, Edwards R, Landsea, C. 2007. Extreme weather records: compilation, adjudication, and publication. Bull. Amer. Meteor. Soc.. 88: 853-860. https://doi.org/10.1175/BAMS$\underline{88-6-853}$

Cook NJ. 2014. Review of errors in archived wind data. Weather, 69: 72-78. https://doi.org/10.1002/wea.2148

Department for Transport. 2014. Transport resilience review: a review of the resilience of the transport network to extreme weather events. Crown copyright. Available from https://www.gov.uk/government/publications/transport-resilience-review-recommendations (accessed 25 February 2019).

Eden P. 2008. Great British Weather Disasters. Continuum. London. 351pp. 
Geurts H. 1975. A thundery cold front in January 1974. Weather, 30: 127-129. https://doi.org/10.1002/j.1477-8696.1975.tb03349.x

Green, A. 2010. From Observations to Forecasts - Part 7. A new meteorological monitoring system for the United Kingdom's Met Office. Weather, 65: 272-277. https://doi: 10.1002/wea.649

Hewston R, Dorling SR. 2011. An analysis of observed daily maximum wind gusts in the UK. $J$. Wind Eng. Ind. Aerodyn.. 99: 845-856. https://doi.org/10.1016/j.jweia.2011.06.004

Keane T, Sheahan MF. 1974. Storms of January 1974. Met Éireann internal memorandum 79/74, 20pp. Available from https://www.met.ie/cms/assets/uploads/2017/08/Jan1974_Storm.pdf (accessed 5 February 2019).

Kendon M, McCarthy M. 2015. The UK's wet and stormy winter of 2013/2014. Weather, 70: 4047. https://doi.org/10.1002/wea.2465

Lamb HH. 1991. Historic Storms of the North Sea, British Isles and Northwest Europe. Cambridge University Press, 204pp.

Met Office. 1974a. Daily Weather Report, January 1974. Available from https://digital.nmla.metoffice.gov.uk/digitalFile_e161b0ba-6258-4802-bc6e-8489f3da1051/ (accessed 5 February 2019].

Met Office. 1974b. Monthly Weather Report, January 1974. Available from https://digital.nmla.metoffice.gov.uk/file/sdb\%3AdigitalFile\%7C8a52e819-224a-49db-9fce0814091514a6/ (accessed 5 February 2019].

Met Office. 1981. Handbook of Meteorological Instruments, Vol. 4, Measurement of Surface Wind. 2nd ed. Her Majesty's Stationery Office, London.

Met Office. 2012. Met Office Integrated Data Archive System (MIDAS) land and marine surface stations data (1853-current). NCAS British Atmospheric Data Centre, accessed on multiple dates between 2012 and 2016. http://catalogue.ceda.ac.uk/uuid/220a65615218d5c9cc9e4785a3234bd0 (accessed 22 February 2019). 
Met Office. 2019a. UK climate - Extremes. Highest gust speed records by country and district (lowlevel sites). Available from: https://www.metoffice.gov.uk/public/weather/climateextremes/\#?tab=climateExtremes (accessed 22 February 2019).

Met Office. 2019b. Met Office Surface Data Users Guide. Available from https://artefacts.ceda.ac.uk/badc_datadocs/ukmo-midas/ukmo_guide.html (accessed 11 April 2019).

Miller C, Holmes J, Henderson D, Ginger J, Morrison M. 2013. The response of the Dines anemometer to gusts and comparisons with cup anemometers. J. Atmos. Oceanic Technol., 30: 13201336. https://doi.org/10.1175/JTECH-D-12-00109.1

Palutikof JP, Holt T, Skellern A. 1997. Wind: Resource and Hazard, Chapter 11 in Hulme M and Barrow E (eds.) Climates of the British Isles: Present, Past and Future. Routledge, London.

Palutikof JP, Brabson BB, Lister DH, Adcock ST. 1999. A review of methods to calculate extreme wind speeds. Meteorol. Appl.. 6: 119-132. https://doi.org/10.1017/S1350482799001103.

Pike WS. 1989: One hundred years of the Dines pressure-tube anemometer. Meteorol. Mag., 118: 209-214.

Prahl BF, Rybski D, Burghoff O, Kropp JP. 2015. Comparison of storm damage functions and their performance. Nat. Hazards Earth Syst. Sci., 15: 769-788. https://doi.org/10.5194/nhess-15-769$\underline{2015}$.

Purevjav G and Coauthors. 2015. The Tosontsengel Mongolia world record sea-level pressure extreme: spatial analysis of elevation bias in adjustment-to-sea-level pressures. Int. J. Climatol., 35 : 2968-2977. https://doi.org/10.1002/joc.4186

Sanders F, Gyakum JR. 1980. Synoptic-dynamic climatology of the "bomb". Mon. Wea. Rev., 108: 1589-1606. https://doi.org/10.1175/1520-0493(1980)108<1589:SDCOT>2.0.CO;2 
Saunders MA, Lea AS. 2017. Methodology for computation of UK windstorm gust return levels on a high spatial resolution $(100 \mathrm{~m})$ grid. UCL Department of Space \& Climate Physics report version 1.4, 6pp. http://discovery.ucl.ac.uk/10071923 (accessed 8 April 2019).

Shellard HC. 1976. Wind, Chapter 3 in Chandler TJ and Gregory S (eds.) The Climate of the British Isles. Longman Press Ltd, London and New York.

Smith SG, 1981. Comparison of wind speeds recorded by pressure-tube and Meteorological Office electrical cup generator anemographs. Meteorol. Mag., 110: 288-301.

370

World Meteorological Organization (WMO), 1987. The Measurement of Gustiness at Routine Wind Stations: A Review (ACM Beljaars). Instruments and Observing Methods Report No. 31. Geneva.

374

World Meteorological Organization (WMO), 2014. WMO No.8 - Guide to Meteorological 376 Instruments and Methods of Observation (CIMO guide) (Updated version, May 2017). Geneva, 1139 pp. 
Figures and captions

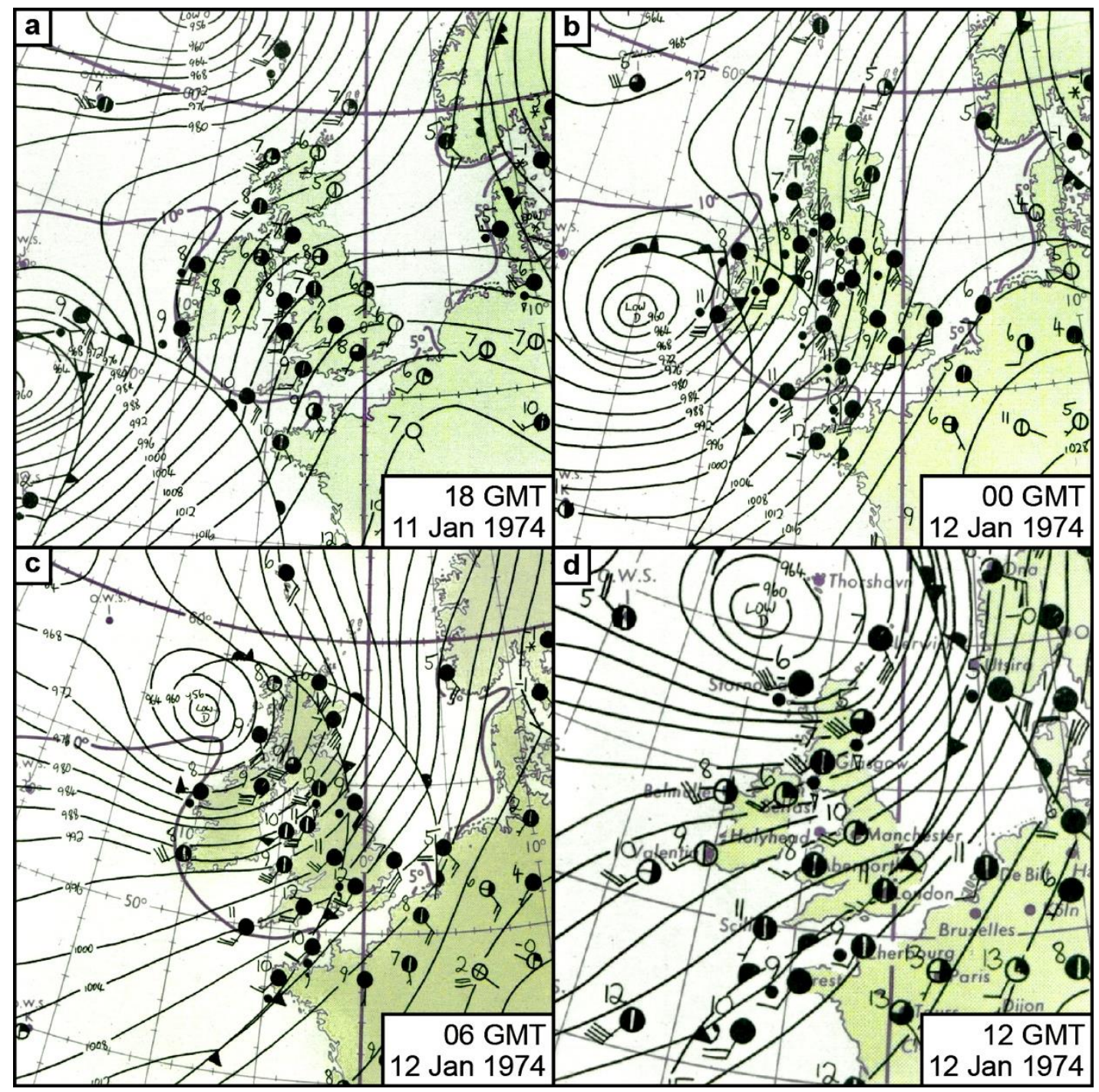

Figure 1. Charts of mean sea level pressure and surface observations around the time of the Kilkeel gust event. The panels display synoptic data centred on Northern Ireland at six hour intervals between (a) 1800 GMT on 11 January 1974 and (d) 1200 GMT on 12 January 1974 (Met Office, 1974a). 


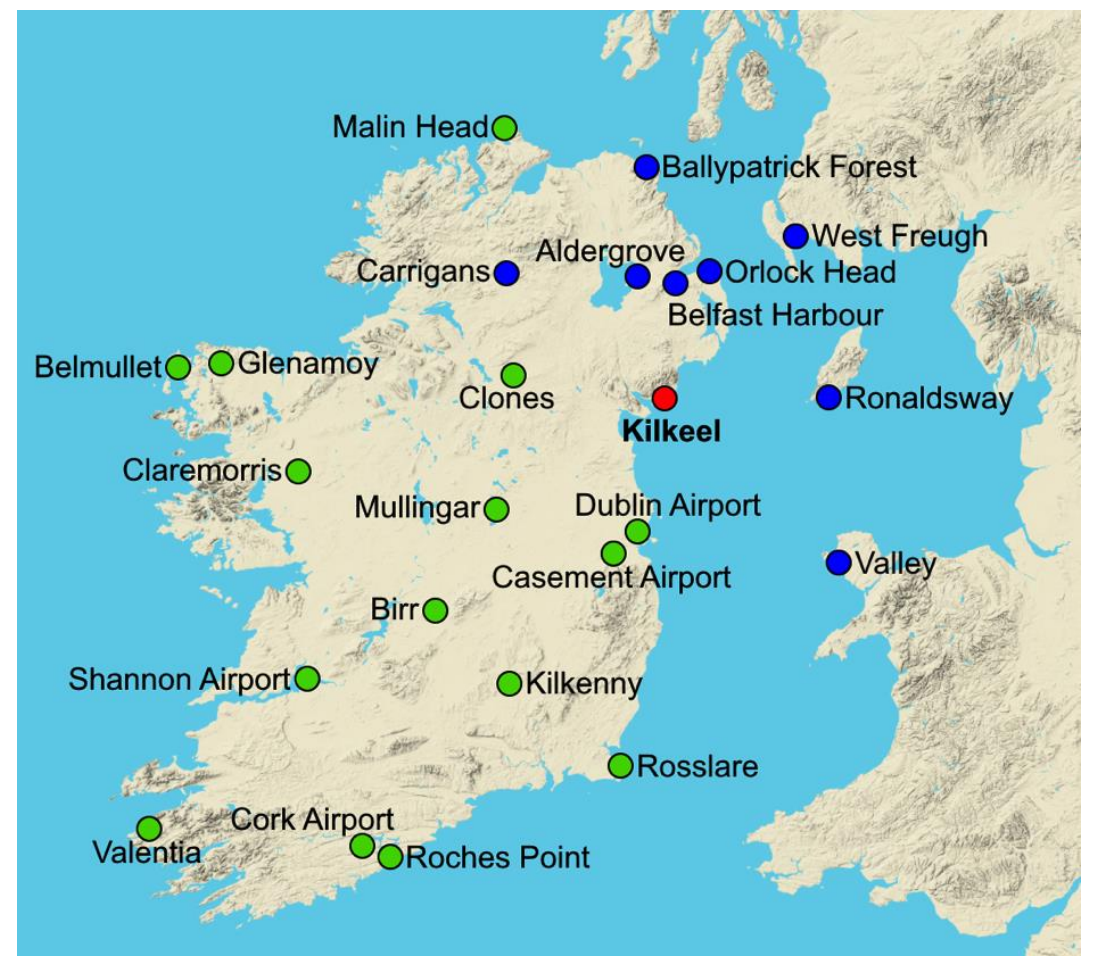

Figure 2. Map showing the location of Kilkeel and surrounding anemometer stations that were operating on 12 January 1974. Met Éireann and Met Office stations are distinguished by green and blue/red circles respectively. 

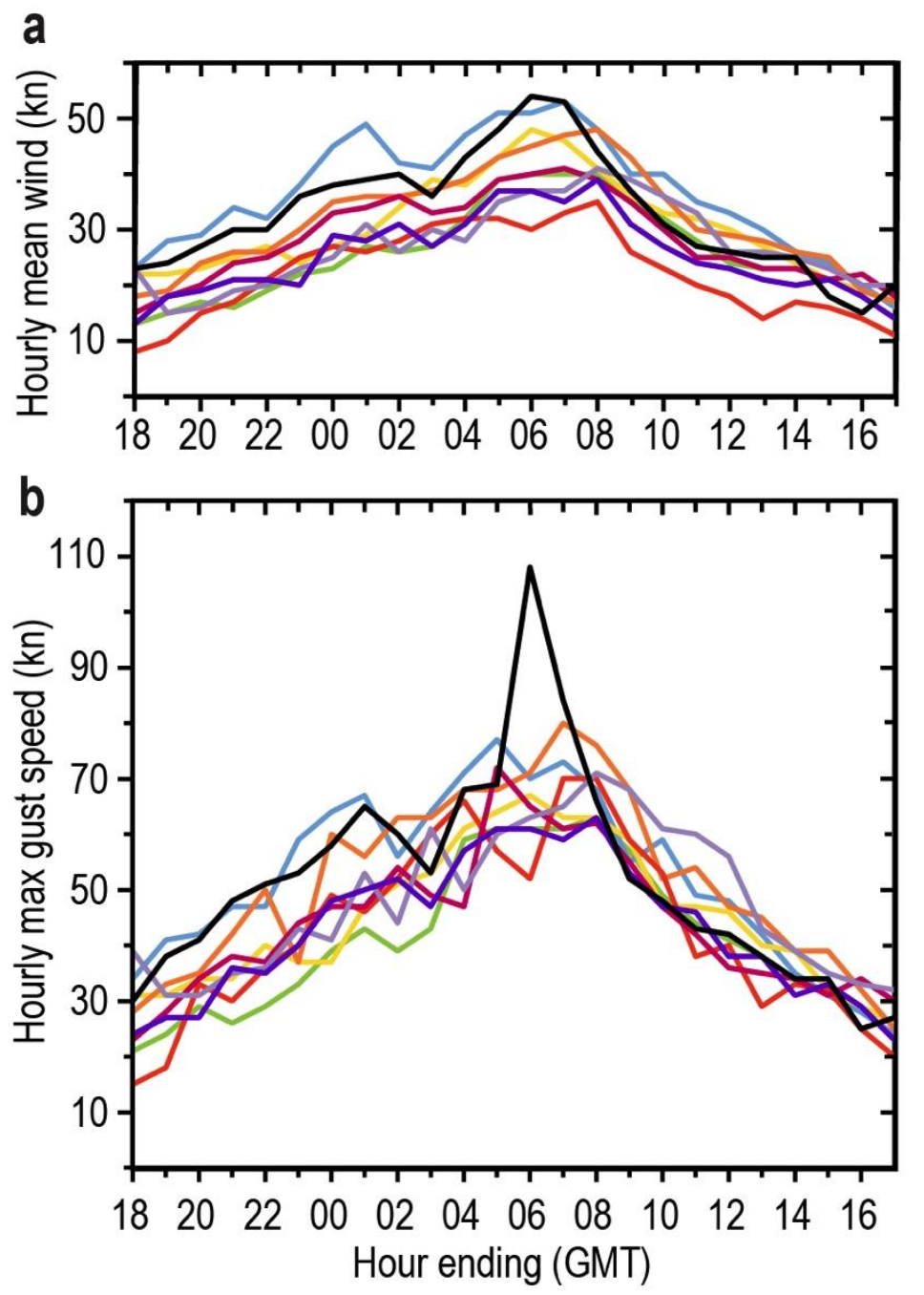

- Kilkeel - Aldergrove - Ballypatrick Forest

— Belfast Harbour — Carrigans — Orlock Head

- Ronaldsway _ West Freugh — Valley

Figure 3. Comparison of the (a) hourly mean wind speeds and (b) hourly maximum gusts recorded at Kilkeel and at the eight nearest Met Office stations. Data are shown for the 24 hour period between hours ending 1800 GMT on 11 January and 1700 GMT on 12 January 1974. 


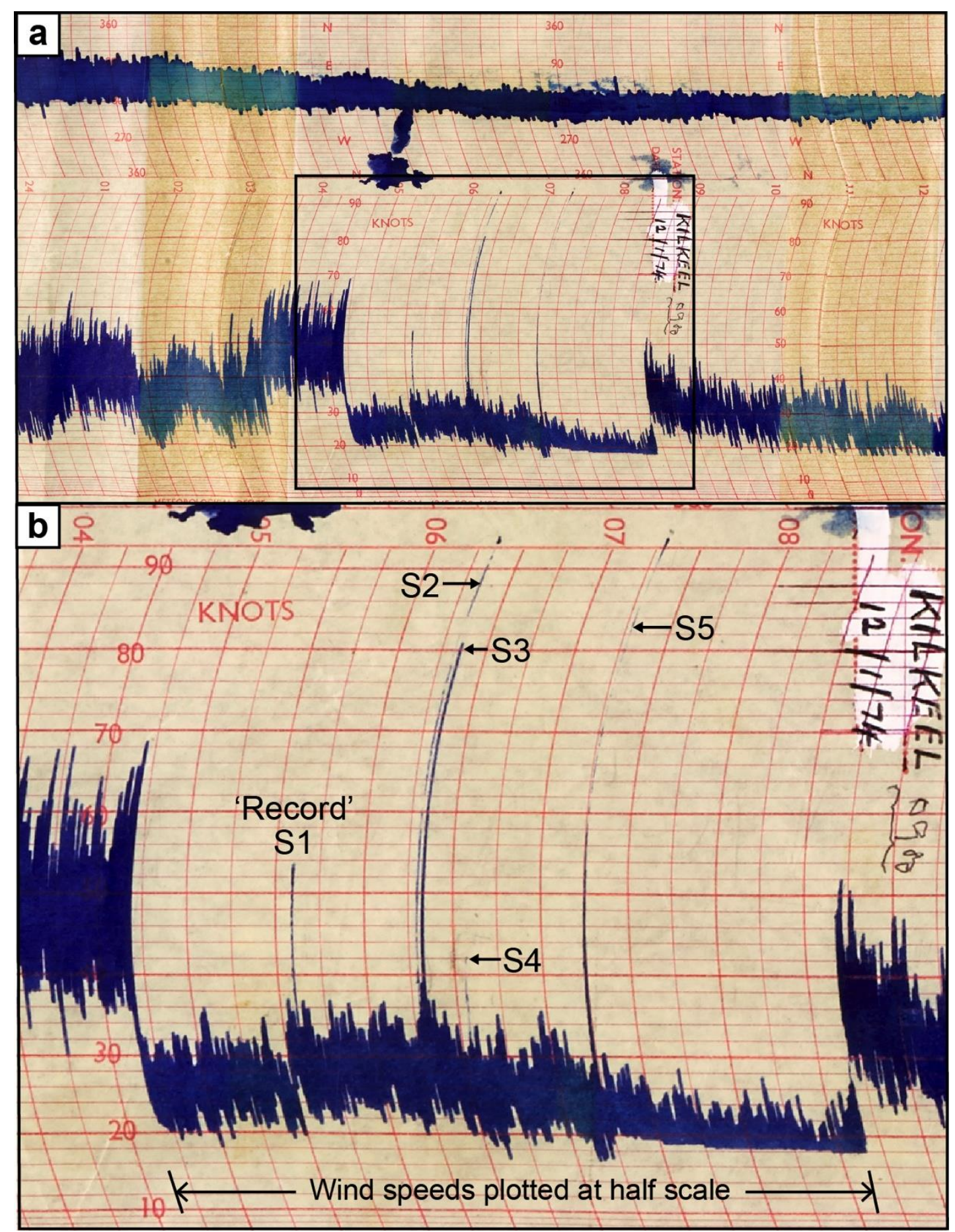

Figure 4. Kilkeel anemogram for 12 January 1974. Panel (a) displays wind direction (upper trace) and wind speed (lower trace) for the 12 hour period starting at 00 GMT. Panel (b) shows a magnified portion of the anemogram data in the black rectangular area in (a) covering 0400-0900 GMT approximately. The scales for time (GMT) and windspeed (kn) are shown in red on the horizontal and vertical chart axes respectively. 
Table 1. Maximum gusts recorded on 12 January 1974 at the fifteen Met Éireann stations shown in Figure 2 (from Keane and Sheahan, 1974).

\begin{tabular}{lll|llc}
\hline Station & $\begin{array}{l}\text { Gust time } \\
(\text { GMT })\end{array}$ & $\begin{array}{l}\text { Max gust } \\
(\mathrm{kn})\end{array}$ & Station & $\begin{array}{l}\text { Gust time } \\
(\text { GMT })\end{array}$ & $\begin{array}{l}\text { Max gust } \\
(\mathrm{kn})\end{array}$ \\
\hline Cork Airport & 0258 & 94 & Kilkenny & 0302 & 77 \\
Valentia & 0017 & 86 & Rosslare & 0401 & 76 \\
Birr & 0455 & 85 & Mullingar & 0528 & 76 \\
Roches Point & 0314 & 83 & Dublin Airport & 0634 & 75 \\
Malin Head & 0800 & 79 & Clones & 0618 & 74 \\
Shannon Airport & 0429 & 79 & Claremorris & 0602 & 65 \\
Belmullet & 0600 & 78 & Glenamoy & 0559 & 64 \\
Casement Airport & 0345 & 77 & & & \\
\hline
\end{tabular}


Table 2. Extreme gust 'spikes' shown on the Kilkeel anemogram in Figure 4.

\begin{tabular}{llll}
\hline $\begin{array}{l}\text { Event marker } \\
\text { (Figure 4) }\end{array}$ & $\begin{array}{l}\text { Event time } \\
(\text { GMT })\end{array}$ & $\begin{array}{l}\text { Gust speed } \\
(k n)\end{array}$ & $\begin{array}{l}\text { Hourly mean wind } \\
\text { speed }(\mathrm{kn})\end{array}$ \\
\hline S1 'Record' & $\mathbf{0 5 3 6}$ & $\mathbf{1 0 8}$ & $\mathbf{5 4}$ \\
S2 & 0618 & 190 & 53 \\
S3 & 0620 & 162 & 53 \\
S4 & 0635 & 84 & 53 \\
S5 & 0715 & 190 & 44 \\
\hline
\end{tabular}

All wind speeds assume a switch to half-scale recording as described in main text.

The event in bold is the longstanding wind gust record for Northern Ireland. Hourly mean wind speed is manually evaluated on the hour for the preceding hour. 
Table 3. Summary of the evidence for and against the veracity of the $108 \mathrm{kn}$ Kilkeel gust recorded on 12 January 1974.

\section{For:}

- High hourly mean winds occurred at Kilkeel and other stations.

- High gusts were recorded elsewhere; notably $114 \mathrm{kn}$ at Great Dun Fell (located in the Pennines at $847 \mathrm{~m}$ elevation), and $94 \mathrm{kn}$ at Cork Airport.

- Significant storm damage occurred in the Republic of Ireland.

\section{Against:}

- The Kilkeel anemograph also recorded 'gusts' of $190 \mathrm{kn}$ (twice) and $162 \mathrm{kn}$. These extreme 'gusts' cannot be genuine.

- The $108 \mathrm{kn}$ 'gust' event is very similar in nature to the clearly-spurious $190 \mathrm{kn}$ and $162 \mathrm{kn}$ 'gust' events. Thus it too cannot be genuine.

- Based upon a probability of exceedance analysis of the entire Kilkeel wind record, the alleged $108 \mathrm{kn}$ gust would have a return period in excess of 1 million years (Saunders and Lea, 2017); it is also 30 per cent greater than the second-highest gust on record for Kilkeel.

- There are no reports of storm damage in Kilkeel compatible with that expected from one or more gusts in excess of $100 \mathrm{kn}$. Indeed, the worst storm damage occurred in southwest Ireland rather than in Northern Ireland.

- Discounting the anomalous gusts, the highest likely genuine gust at Kilkeel was 78 kn, which both matches well the level of the highest gusts recorded at surrounding stations on this occasion, and is a much closer statistical fit to other extreme gusts recorded at the site over the period 1969 to 2013. 